\title{
Furosemide Alters Organ of Corti Mechanics: Evidence for Feedback of Outer Hair Cells upon the Basilar Membrane
}

\author{
Mario A. Ruggero and Nola C. Rich \\ Department of Otolaryngology, University of Minnesota, Minneapolis, Minnesota 55414
}

\begin{abstract}
A widely held hypothesis of mammalian cochlear function is that the mechanical responses to sound of the basilar membrane depend on transduction by the outer hair cells. We have tested this hypothesis by studying the effect upon basilar membrane vibrations (measured by means of either the Mössbauer technique or Doppler-shift laser velocimetry) of systemic injection of furosemide, a loop diuretic that decreases transduction currents in hair cells. Furosemide reversibly altered the responses to tones and clicks of the chinchilla basilar membrane, causing response-magnitude reductions that were largest (up to $61 \mathrm{~dB}$, averaging 25-30 $\mathrm{dB}$ ) at low stimulus intensities at the characteristic frequency (CF) and small or nonexistent at high intensities and at frequencies far removed from CF. Furosemide also induced response-phase lags that were largest at low stimulus intensities (averaging $77^{\circ}$ ) and were confined to frequencies close to CF. These results constitute the most definitive demonstration to date that mechanical responses of the basilar membrane are dependent on the normal function of the organ of Corti and strongly implicate the outer hair cells as being responsible for the high sensitivity and frequency selectivity of basilar membrane responses. A corollary of these findings is that sensorineural hearing deficits in humans due to outer hair cell loss reflect pathologically diminished vibrations of the basilar membrane.
\end{abstract}

There is accumulating evidence that the basilar membrane and outer hair cells sustain a positive feedback relationship, such that basilar mcmbrane vibrations induce receptor potentials in outer hair cells that, in turn, boost the mechanical response of the basilar membrane at low sound levels in a frequency-selective manner (Kemp, 1978; Kim et al., 1980; Weiss, 1982; Davis, 1983; Mountain et al., 1983; for review, see Dallos, 1988). Most support for this hypothesis has come not from basilar membrane recordings, but rather from the effects of cochlear manipulations upon sound-evoked otoacoustic emissions (Anderson and Kemp, 1979; Kim et al., 1980; Mountain, 1980; Siegel and Kim, 1982; Hubbard and Mountain, 1983, 1990; Guinan, 1986; Mountain and Hubbard, 1989) and upon the responses to sound of cochlear afferents and inner hair cells (Kim et al., 1980; Brown et al.,

\footnotetext{
Received Aug. 13, 1990; revised Nov. 13, 1990; accepted Nov. 27, 1990.

This work was principally supported by NIH (National Institute on Deafness and Other Communication Disorders) Grants DC-00110 and DC-00419 and by smaller grants from the Minnesota Medical Foundation and the I ions 5M Hearing Research Endowment.

Correspondence should be addressed to Mario A. Ruggero, Department of Otolaryngology, University of Minnesota, 2630 University Avenue Southeast. Minneapolis, MN 55414.

Copyright (C) 1991 Society for Neuroscience $0270-6474 / 91 / 111057-11 \$ 03.00 / 0$
}

1983; Nuttall, 1985), from the existence of spontaneous otoacoustic emissions (Kemp, 1978), and, circumstantially, from the demonstration of electrically induced motility of outer hair cells in vitro (Brownell et al., 1985; Ashmore, 1987). The observation that basilar membrane vibrations are extremely labile, being easily disrupted by death and surgical procedures involving the cochlea (Rhode, 1973; Khanna and Leonard, 1982; Sellick et al., 1982; Robles et al., 1986b) and by acoustic trauma (Patuzzi et al., 1984), may be taken as evidence for a bidirectional relationship between the organ of Corti and the basilar membrane. However, it is not clear which cellular elements are affected by these nonspecific and irreversible cochlear insults.

In the present investigation, we have sought evidence that electromechanical transduction in outer hair cells determines the mechanical response to sound of the basilar membrane. Our approach consisted of studying the effect upon the basilar membrane's response to sound of a specific and reversible alteration of the cochlea, namely reduction of transduction currents in hair cells by an ototoxic loop diuretic, furosemide. Intravenous administration of furosemide is known to cause frequency-specific threshold elevations in the responses of auditory-nerve afferents. Thresholds are elevated for all stimulus frequencies, but threshold elevations are most prominent near the characteristic frequency (CF), that frequency at which each neuron is normally most sensitive (Evans and Klinke, 1982; Sewell, 1984b). Our working hypothesis is that the non-frequency-specific effects of furosemide reflect decreases in the receptor potentials of inner hair cells (Sewell, 1984a,b), while the frequency-specific threshold elevations result from decreases in basilar membrane vibration at near-CF frequencies. The present results, showing CF-specific alterations of basilar membrane mechanics induced by furosemide, strongly support this hypothesis. We shall argue that such mechanical effects are mediated by the outer hair cells.

A preliminary version of these findings has been published (Ruggero and Rich, 1990b).

\section{Materials and Methods}

The vibrational response of the basilar membrane to sound was recorded in the basal turn of 5 chinchilla cochleae, at a site located approximately $3.5 \mathrm{~mm}$ from the oval window. The characteristic frequency of this site is roughly $8.5 \mathrm{kHz}$ (Robles ct al., 1986b). One of 2 measurement methods was used in each cochlea: the Mössbauer technique (Robles et al., 1986b) or laser velocimetry (Ruggero and Rich, 1990a, 1991). The Mössbauer technique measures vibration velocity on the basis of Doppler shifts in photon frequency introduced by the relative motion between a radioactive source, attached to the basilar membrane, and an absorber. In these experiments, the source was a $100-\mu \mathrm{m}$ square of $6-\mu \mathrm{m}$-thick rhodium foil doped with ${ }^{57} \mathrm{Co}$. The absorber $\left({ }^{57} \mathrm{Fe}\right.$-enriched palladium foil) was mounted in front of a proportional counter and the $14.4-\mathrm{keV}$ $\gamma$-photons were selected by means of a single-channel analyzer. The laser-velocimetry method derives vibration velocity from the Doppler 
shift of laser light reflected from a moving target, in our case glass microbeads (diameter, 10-30 $\mu \mathrm{m}$; index of refraction, 2.1) resting on the basilar membrane. The laser beam was directed and focused via a metallurgical microscope cquipped with a $20 \times$ ultralong-working-distance objective. The frequencies of the outgoing and incoming beams (traveling on the same optical axis) were compared by a Doppler-shift detector (a pair of differentially coupled photodiodes) that generated an output electrical current containing the instantaneous Doppler frequency shift. This current was fed to a frequency tracker, which generated a voltage proportional to target velocity.

Preliminary animal preparations were identical for the 2 vibrationmeasurement methods. Chinchillas weighing about $0.5 \mathrm{~kg}$ were anesthetized initially with ketamine $\mathrm{HCl}(100 \mathrm{mg} / \mathrm{kg})$, followed by doses of pentobarbital sufficient to maintain deep anesthesia. The animal was wrapped in a servo-controlled heating pad that kept core temperature (monitored in the rectum) at $38^{\circ} \mathrm{C}$. Tracheotomy and intubation were performed, but forced respiration was usually not necessary. The right femoral vein was cannulated to allow systcmic administration of furosemide (Lasix, Hoechst-Roussel). The left pinna was removed, and the external auditory meatus was enlarged to permit insertion of the tip of a plastic speculum, coupled to a Beyer DT-48 earphone, which was then sealed to the bone with ear impression compound. The left bulla was widely opened, and a silver-wire electrode was placed on the round window as a means of monitoring the compound action potential in response to tone pips. The tensor tympani muscle routinely was cut. A small hole made in the basal turn of the otic capsule allowed visualization of the basilar membrane and placement of either the radioactive Mössbauer source or 1 or a few glass microbeads on the membrane. Depending on the measurement method to be used, either the Mössbauer detector was positioned as near as possible to the opening in the cochlea, or the microscope coupled to the laser was positioned such that the laser beam could be focuscd on the microbeads.

Acoustic stimuli, pure tones and clicks, were generated by a computercontrolled waveform generator (Ruggero and Rich, 1983). Sound pressure amplitude and phase near (within $2 \mathrm{~mm}$ of) the tympanic membrane were calibrated between 30 and $24,000 \mathrm{~Hz}$ by means of a miniature microphone (Knowles 1785) equipped with a metal probe tube. This calibration was stored electronically and was subsequently used in the presentation of sinusoidal stimuli with specified sound pressure levels (SPL; i.e., referenced to $20 \mu \mathrm{Pa}$ ) and phases. With the Mössbauer technique, each tone was presented for $4 \mathrm{sec}$, with $2-4 \mathrm{sec}$ off time. $\gamma$-Photon occurrence times were collected over 25 repetitions, binned into 32-bin period histograms locked to the stimulus, and stored for off-line analysis. Stimuli for laser-velocimetry measurements were tones (3-10 msec on, presented every 15-30 msec) and clicks (acoustic duration, $83 \mu \mathrm{scc}$ at half-height; presented every $20-40 \mathrm{msec}$ ). The voltage output of the Doppler-frequency tracker was band-pass filtered between 26 and $15,000 \mathrm{~Hz}$ and was sampled at rates of 10 or $40 \mathrm{kHz}$. The results, averaged over 1024-2048 stimulus repetitions, were stored for off-line analysis.

Extraction of basilar membrane velocity magnitudes and phases from the $\gamma$-photon period histograms was accomplished using a least-squares fitting program that fit to each histogram 1 cycle of a velocity sinusoid transformed by the Lorentzian function (Robles et al., 1986b). Laservelocimetry data were analyzed by Fourier transformation of the timeaveraged responses. The results presented here were obtained in 3 animals (M154, M155, and M156) using the Mössbauer technique, and in 2 others (L13 and L14) using laser velocimetry. Elevations of compound-action-potential thresholds, as a result of trauma caused by manipulations of the cochlea, were minimal (3-12 $\mathrm{dB}$ at $8 \mathrm{kHz}$ ) at the time of initial basilar membrane recordings in all but 1 chinchilla; the exception was chinchilla M154, which had a 27-dB threshold elevation.

\section{Results}

The purpose of the present experiments was to test the hypothesis that mechanical motion of the basilar membrane of the mammalian cochlea depends on normal transduction in the outer hair cells of the adjacent organ of Corti. This hypothesis was tested by studying the effects of furosemide, an ototoxic diuretic known to disrupt hair cell receptor potentials, on a basilar membrane site located $3.5 \mathrm{~mm}$ from the base of the chinchilla cochlea. After determining the CF of the basilar membrane site, its mechanical responses to $\mathrm{CF}$ and lower-frequency tones and/or clicks were measured before and after intravenous administration of furosemide.

\section{Effects of furosemide on the magnitude of responses to tones}

Upon intravenous administration of furosemide $(50 \mathrm{mg}$; approximately $100 \mathrm{mg} / \mathrm{kg}$ ) to chinchilla $\mathrm{L14}$, there was an immediate and large decrement in the magnitude of basilar membrane responses to tone bursts at CF. The average peak velocity diminished from 278 to $21 \mu \mathrm{m} / \mathrm{sec}$ within the first $14 \mathrm{~min}$ following injection (Fig. 1). Subsequently, responses gradually returned to their original magnitude, almost fully recovering by $105 \mathrm{~min}$. A similar duration has been measured in chinchilla for the depression of the endocochlear potential following equaldosage injections of furosemide (Rybak and Morizono, 1982; see also, for the guinea pig, Kusakari et al., 1978). The time course of recovery of basilar membrane responses to tones also resembled endocochlear potential data in that recovery was biphasic, proceeding more rapidly immediately after injection than at later times.

The effect of furosemide was both stimulus-frequency- and intensity-dependent. Figure 2 compares basilar-membrane input-output functions, measured at various pre- and postinjection times, for tone bursts at $\mathrm{CF}(9 \mathrm{kHz})$ and at a frequency much lower than CF $(1 \mathrm{kHz})$. Before furosemide injection, the input-output function at CF consisted of 3 segments, according to its slope and the stimulus intensity. At low $(<30 \mathrm{~dB})$ and high ( $>90 \mathrm{~dB}$ ) stimulus intensities, its slope was approximately linear ( $1 \mathrm{~dB}$ of response growth per $1 \mathrm{~dB}$ of increase in stimulus level); at intermediate intensities, its slope was much shallower, averaging $0.5 \mathrm{~dB} / \mathrm{dB}$. For low- and moderate-intensity $\mathrm{CF}$ tone bursts, furosemide caused an immediate response reduction as large as $25 \mathrm{~dB}$; at higher stimulus intensities, the response reduction was much smaller. Thus, the overall effect of furosemide on the CF input-output function was to linearize it. In contrast with the strong effects on the nonlinear CF responses, furosemide had no apparent effect on the linear input-output function for responses to $1-\mathrm{kHz}$ tone bursts.

Figure 3 contrasts the effects of furosemide in 2 cochleae lying at the extremes of the range of sensitivity and frequency tuning in our sample. Figure $3 A$ shows input-output functions at $\mathrm{CF}$ $(9 \mathrm{kHz})$ and at $5 \mathrm{kHz}$ for the most sensitive and nonlinear basilar membrane (I.13) that we have studied. [Normal responses of this basilar membrane to tones and clicks have been published elsewhere (Ruggero and Rich, 1991).] Over the range of 20-60 dB SPL, prefurosemide responses to CF tones grew at a highly compressive rate of $0.25 \mathrm{~dB} / \mathrm{dB}$. Even at the lowest stimulus intensities for which data are available (3-20 dB), the inputoutput slope was no higher than $0.6 \mathrm{~dB} / \mathrm{dB}$. Upon furosemide injection, there were huge decreases in responses to low- and moderate-intensity stimuli. These decreases were so large that reliable measurement of the immediate effects of furosemide injection could not be obtained for low-intensity stimuli. If measured as velocity change at a particular stimulus intensity, CF responses were decreased by at least $30 \mathrm{~dB}$ for stimulus intensities up to $50 \mathrm{~dB}$ SPL. When measured as a horizontal shift along the stimulus-intensity axis (i.c., the dB difference in stimulus intensities, postinjection minus preinjection, that yielded a velocity of $100 \mu \mathrm{m} / \mathrm{sec}$ ), the decrement was larger than $61 \mathrm{~dB}$. This was the largest effect of furosemide in the present experimental series. At higher stimulus intensities (or larger velocity criteria), the effect of furosemide was progressively smaller. By 43 min postinjection, partial recovery of responses had oc- 

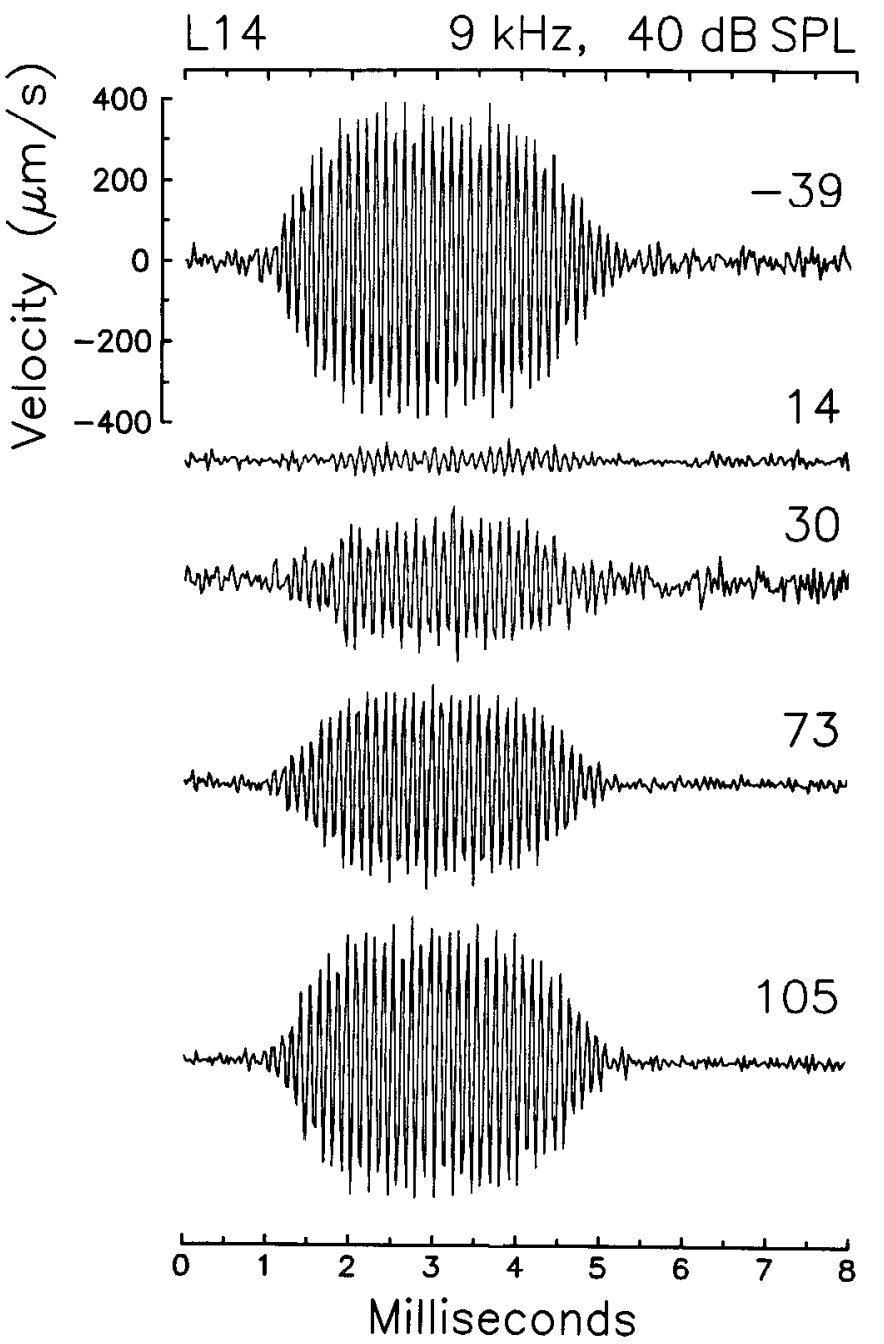

Figure 1. Effect of an intravenous furosemide injection upon basilar membrane responses to CF tone pips ( $9 \mathrm{kHz}, 40 \mathrm{~dB}$ SPL). Each waveform, recorded with laser velocimetry, represents the average velocity response to 1024 presentations of a $3.8-\mathrm{msec}$ tone burst. The time of data collection, in minutes relative to injection time, is indicated for each response (numbers to right).

curred, equivalent to a stimulus shift of 16-19 dB. No further recovery took place in this cochlea, possibly for reasons unrelated to the furosemide injection. In contrast with the highly nonlinear preinjection input-output function at $\mathrm{CF}$, responses at $5 \mathrm{kHz}$ were essentially linear and were unaffected by furosemide.

Figure $3 B$ illustrates results from another cochlea, M154, that are qualitatively similar to those shown in Figures 2 and $3 \mathrm{~A}$ (and in Ruggero and Rich, 1990b, their Fig. 2): furosemide induced decreases in responses to low-intensity CF tones, with smaller effects at higher intensities, while responses to low-frequency tones were not altered. Basilar membrane M154 was the least sensitive one in the present series and yielded the smallest effect of furosemide injection. Using as a criterion the stimulus SPL required to produce a $100-\mu \mathrm{m} / \mathrm{sec}$ response velocity, the net effect of furosemide injections in 5 cochleae had a median value of $24.5 \mathrm{~dB}$ and a mean $( \pm \mathrm{SD})$ of $30.1 \pm 17.1 \mathrm{~dB}$. It is important to note that these data were obtained with dissimilar furosemide dosage, ranging from 50 to $100 \mathrm{mg} / \mathrm{kg}$. Nevertheless,

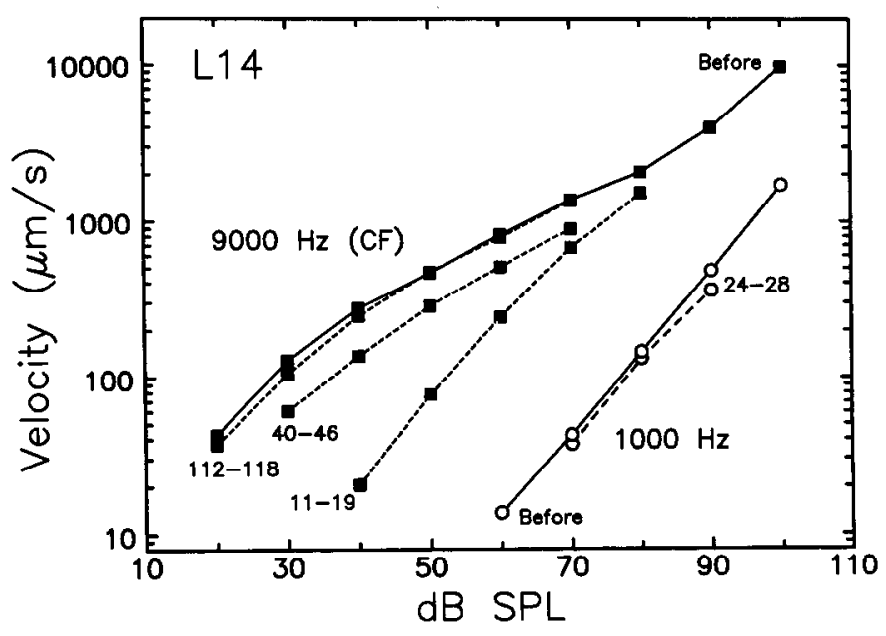

Figure 2. Input-output curves for the response of basilar membrane L14 to tones immediately preceding (solid line) and following (broken lines) an intravenous 50-mg furosemide injection. Responses are shown for a CF tone ( $9 \mathrm{kHz}$, squares) and for a $1-\mathrm{kHz}$ tone (circles). The abscissa indicates stimulus intensity (in dB SPL; i.e., referenced to $20 \mu \mathrm{Pa}$ ), and the ordinate indicates peak basilar membrane velocity (in $\mu \mathrm{m} / \mathrm{sec}$ ). The time of data collection, in minutes relative to the furosemide injection, is indicated for each curve. Data were collected by means of laser velocimetry.

most of the variability in the magnitude of the net effect of furosemide apparently can be attributed to the initial sensitivity of basilar membrane responses: there was a clear correlation ( $r$ $=0.85$; slope, $1 \mathrm{~dB} / \mathrm{dB}$ ) between the preinjection basilar membrane sensitivity and the net effect of furosemide. Preinjection, the sound intensities at $100 \mu \mathrm{m} / \mathrm{sec}$ had a mean $( \pm \mathrm{SD})$ of 32.5 $\pm 15.3 \mathrm{~dB}$; the corresponding postinjection mean was $62.6 \pm$ $9.0 \mathrm{~dB}$.

Concurrently with measurements of basilar membrane vibration, the effects of furosemide injection were studied by recording compound-action-potential (CAP) thresholds. Furosemide induced CAP threshold elevations ranging from 24 to 46 $\mathrm{dB}$. With but 1 exception, CAP threshold elevations exceeded the decreases in basilar membrane sensitivity, with a median difference of $11.5 \mathrm{~dB}$. This is as predicted by our working hypothesis, which states that the effects of furosemide on auditorynerve afferents result from the combination of 2 distinct effects: a CF-specific reduction of basilar membrane mechanical sensitivity and a decrease in the transduction gain of inner hair cells, which is not frequency dependent.

\section{Effects of furosemide on the magnitude of responses to clicks}

In order to study in more detail the frequency dependence of the effects of furosemide, clicks were used as stimuli, and the basilar membrane responses were Fourier transformed to obtain velocity frequency spectra (Ruggero and Rich, 1991). Figure 4 illustrates the effect of a 50-mg furosemide injection upon responses to 55-dB (peak-pressure) clicks in chinchilla L14. The preinjection response consisted of a relatively undamped oscillation with fundamental period of $102 \mu \mathrm{sec}$. The oscillation displayed some frequency modulation, with the initial oscillation cycles being substantially longer than later ones. The envelope of the oscillation, resembling a somewhat asymmetric spindle and encompassing some 10 or 11 resolvable cycles, peaked at about $1.8 \mathrm{msec}$ following stimulus onset. (No correction has been used here to compensate for approximately 270 


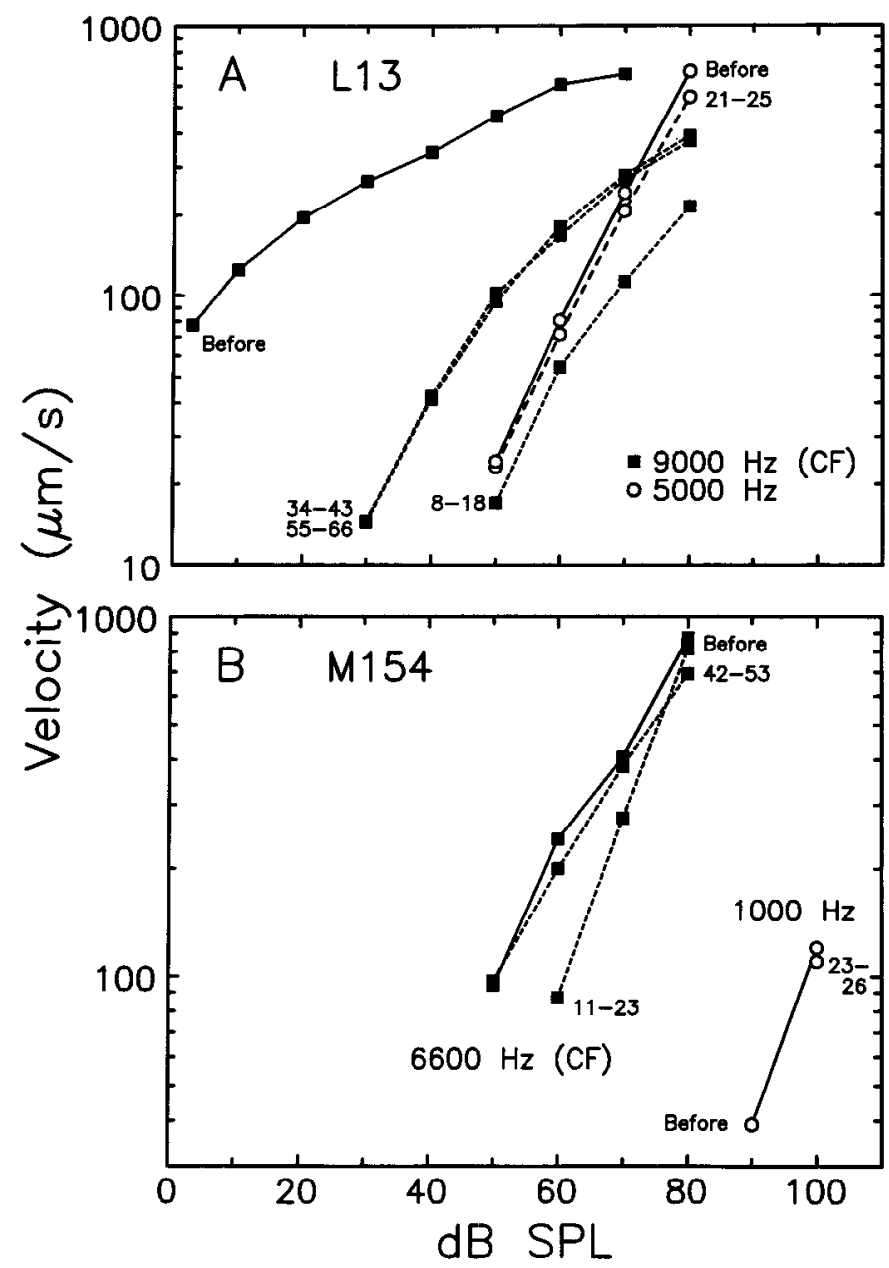

Figure 3. Input-output curves for the responses to tones of 2 basilar membranes at times immediately preceding (solid lines) and following (broken lines) intravenous furosemide injection. $A$, Responses of basilar membrane L13 are shown for a CF tone ( $9 \mathrm{kHz}$, squares) and for a $5-\mathrm{kHz}$ tone (circles). Furosemide dosage, $25 \mathrm{mg}$. Data were collected by means of laser velocimetry. $B$, Responses of basilar membrane M154 are shown for $\mathrm{CF}(6.6 \mathrm{kHz}$, squares) and $1-\mathrm{kHz}$ tones (circles). Furosemide dosage, $40 \mathrm{mg}$. Data were collected by means of the Mössbauer technique. The time of data collection, in minutes relative to injection time, is indicated for each response.

$\mu \mathrm{sec}$ of acoustic and other stimulus-system delays.) Upon furosemide injection, most of the response to the clicks was abolished, cxcept for the initial cycle of oscillation, which was reduced by $50 \%$ or less. By 46 min postinjection, this initial response cycle was fully recovered, but later cycles, including those that were largest before injection, remained depressed. Recovery was essentially complete by $100 \mathrm{~min}$ postinjection.

In Figure 5, preinjection frequency spectra from animal L14 are contrasted with spectra of responses obtained immediately following a furosemide injection and after full recovery. Results are shown for clicks at 3 peak intensities: 55, 75, and $95 \mathrm{~dB}$. The preinjection spectra varied nonlinearly with stimulus intensity: bandwidths were narrow in responses to 55 - $\mathrm{dB}$ clicks and relatively wide at 75 and $95 \mathrm{~dB}$ SPL. In addition, the largest spectral components of the responses shifted to lower frequencies with increasing stimulus intensity. These changes resulted in a sharp deterioration of frequency tuning at high stimulus intensities.

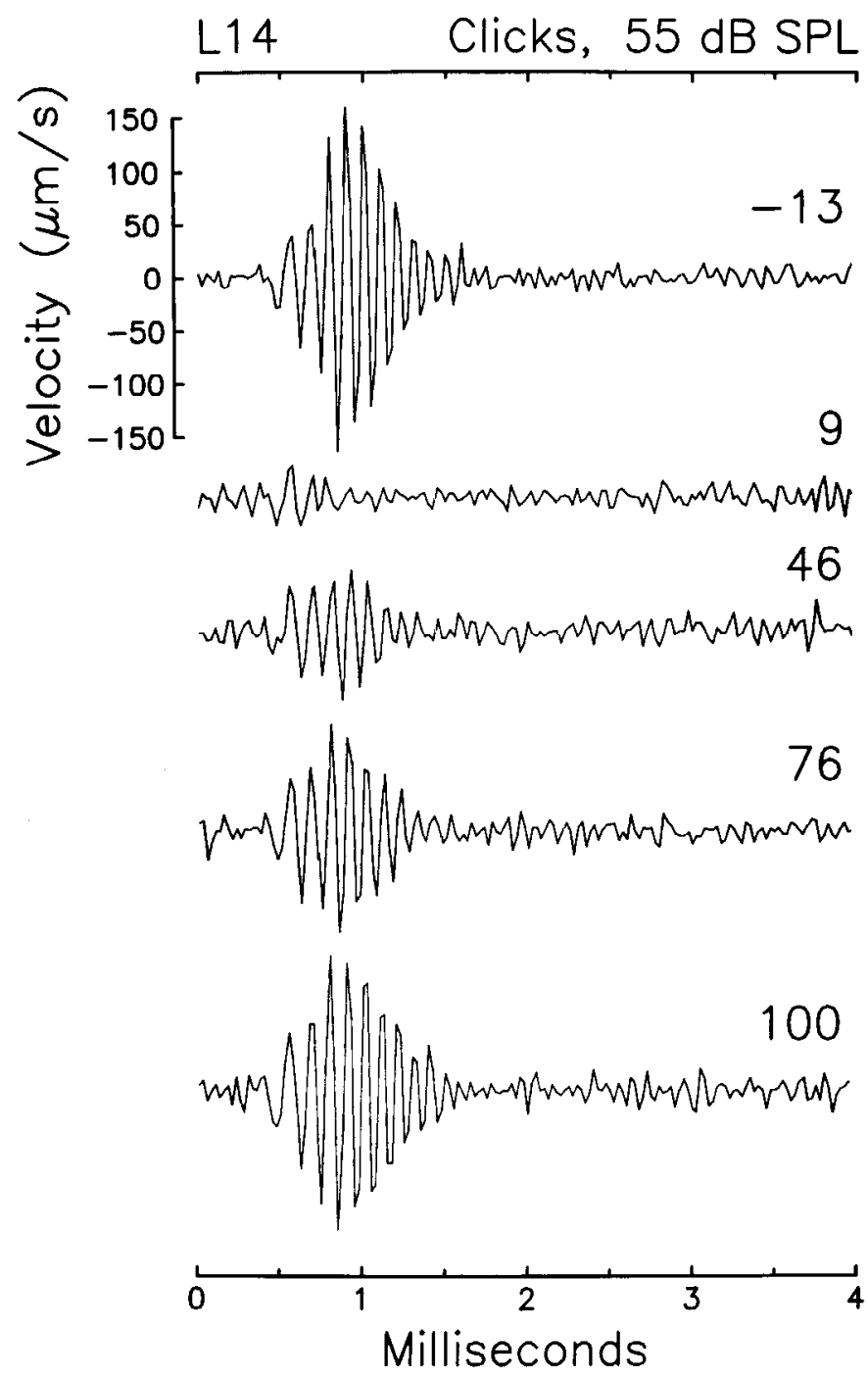

Figure 4. Effect of furosemide injection upon basilar-membrane velocity responses to clicks. The abscissa indicates elapsed time from stimulus onset. Each trace represents the averaged response to 2048 stimulus presentations. The time of data collection, in minutes relative to furosemide injection, is indicated for each response (numbers to right). Data were collected by means of laser velocimetry.

Upon furosemide injection, the responses to the $55-\mathrm{dB}$ clicks were drastically reduced, by at least $20 \mathrm{~dB}$ at frequencies near $\mathrm{CF}$, to levels below the noise floor of measurement. Responses to $75-$ and $95-\mathrm{dB}$ clicks illustrate the strong frequency dependence of the effect of furosemide: the largest decrement in response sensitivity occurred near CF (approximately $9.8 \mathrm{kHz}$ ), while spectral components sufficiently distant from $\mathrm{CF}$ were unaffected. This frequency-selective decrease in sensitivity resulted in a decrease in the sharpness of frequency tuning and a downward shift of the frequency of maximal sensitivity. As shown above for responses to $\mathrm{CF}$ tones, the effects of furosemide upon responses to clicks were also dependent on stimulus intensity. While near-CF response reductions were greater than $25 \mathrm{~dB}$ for 55 - and $75-\mathrm{dB}$ clicks, such reductions were no larger than $10 \mathrm{~dB}$ for 95 -dB clicks. Similarly, the furosemide-induced changes in frequency tuning were large at low stimulus intensities but became less pronounced at high intensities. Full recovery of responses (including, perhaps, an overshoot) took place 
by 100 min postinjection. Results qualitatively similar to those for L14 were obtained in another chinchilla (L13, not shown). Table 1 presents for these 2 chinchillas the frequency of maximal response, $10-\mathrm{dB}$ bandwidth, and frequency of largest response divided by the $10-\mathrm{dB}$ bandwidth $\left(Q_{10}\right)$ for both normal (preinjection) and postinjection responses to clicks.

\section{Efferts of furosemide on response phases}

Figure 6 shows the phase-versus-frequency characteristics of click-evoked basilar membrane responses before and after a 25 mg injection of furosemide. The phases were computed by Fourier transformation of the responses of animal $\mathrm{L} 13$ to $75-\mathrm{dB}$ clicks. [Phases are presented in Figs. 6-10 only for responses with magnitudes larger than a (arbitrary) criterion.] The phase curves consist of monotonically increasing lags as a function of increasing frequency. While there was no discernible effect of the furosemide injection for spectral frequencies below $5.5 \mathrm{kHz}$, postinjection phases lagged preinjection values substantially at frequencies at which the largest prefurosemide responses occurred. The furosemide-induced phase lag diminished with the passage of time.

In order to assess the net effect of furosemide injection upon the phases of responses to clicks (i.e., in isolation from the variation of phasc as a function of spectral frequency), postinjection response phases relative to preinjection values for 2 basilar membranes (for which CFs, 10 -dB bandwidths, and $Q_{10} \mathrm{~s}$ are given in Table 1) are presented in Figure 7, plotted as a function of frequency. That is, the click-response phases before furosemide injection have been subtracted from postinjection response phases to same-level clicks. The phase-versus-frequency characteristics consist of frequency- and intensity-dependent phase lags: the phase lags are largest for low-intensity clicks in the spectral region immediately below CF (Fig. 7, arrows). Thus, the degree of furosemide-induced phase lag appears to covary with reduction in response magnitude (such as seen in Fig. 5).

The phases of responses of 2 basilar membranes to tones near $\mathrm{CF}$ and at one lower frequency, before and after furosemide injections, are plotted in Figure 8 as a function of stimulus level; the phases of $A$ and $B$ correspond to the magnitude data of Figures $3 A$ and 2 , respectively. The phases of the preinjection responses to near-CF tones varied as a function of stimulus intensity. In the case of L13 (Fig. 8A), there was a progressive phase lead with increasing stimulus intensity, accumulating to nearly $+120^{\circ}$ as intensity was raised from 3 to $40 \mathrm{~dB}$ SPL; above $40 \mathrm{~dB}$ there was little further phase change. In the case of L14 (Fig. $8 B$ ), CF response phases remained relatively stable in the range of 20-70 dB SPL; above $70 \mathrm{~dB}$ there was an abrupt change, with an accumulated phase lag of nearly $-100^{\circ}$ at $100 \mathrm{~dB}$. Intensity-dependent phase shifts have been previously noted in responses of the auditory nerve (Anderson et al., 1971) and the basilar membrane (Rhode and Robles, 1974; Geisler and Rhode, 1982; Sellick et al., 1982). Phase lags were found to accompany intensity increases for stimuli with frequencies lower than CF, while phase leads occurred for intensity increases at frequencies above CF. Therefore, it would appear that $9-\mathrm{kHz}$ tones may have been actually somewhat below and above CF for the basilar membrane sites studied in L14 and L13, respectively. In the case of L14, this possibility is supported by an independent assessment of $\mathrm{CF}$, based on responses to clicks: for the lowest click intensity $(55 \mathrm{~dB})$, the CF for L14 was $9.8 \mathrm{kHz}$. However, measurements of the response of basilar membrane L13 to 55-

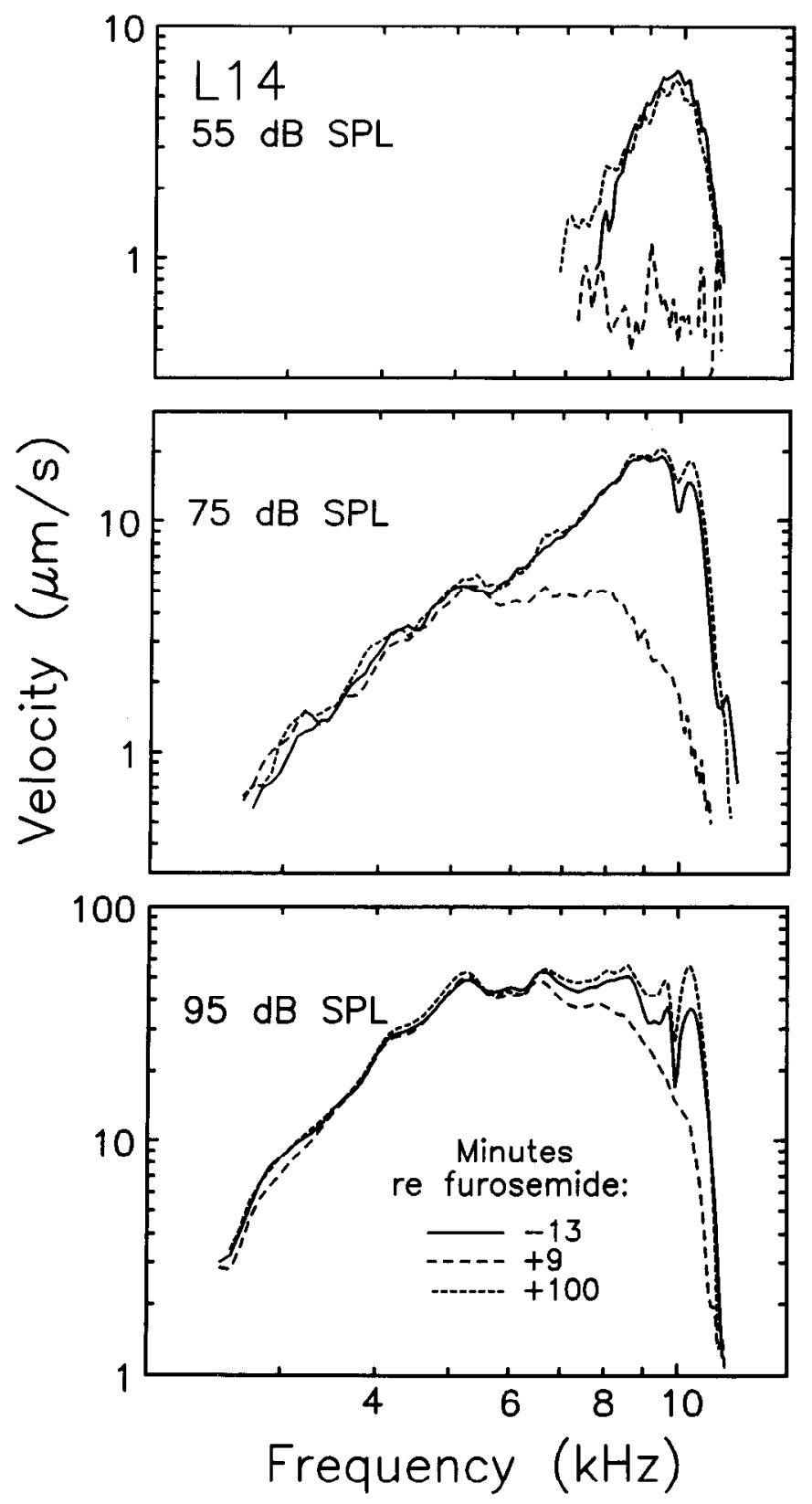

Figure 5. Effect of a furosemide injection upon the frequency dependence of the magnitude of basilar-membrane responses to clicks. The velocity-magnitude frequency spectra were obtained by Fourier transformation of responses to 55-, 75-, and 95-dB SPL clicks. In each panel, the abscissa indicates frequency, and the ordinate indicates spectral magnitude in $\mu \mathrm{m} / \mathrm{sec}$. For each stimulus level, 3 curves are displayed, representing responses immediately preceding (solid line) and following (long-dash line) a furosemide injection and when full response recovery had occurred (short-dash line). Data were collected using laser velocimetry in basilar membrane L14.

$\mathrm{dB}$ clicks (Fig. 5) indicate that $9 \mathrm{kHz}$ actually matches $\mathrm{CF}$ closely.

As shown above for the responses to clicks, furosemide induced phase lags in the responses to tones that were both frequency and intensity dependent. There was little or no phase change after the furosemide injection in the responses to frequencies well below $\mathrm{CF}(5 \mathrm{kHz}$ for $\mathrm{L} 13,1 \mathrm{kHz}$ for $\mathrm{L} 14$; Fig. $8 A, B$, respectively). In contrast, for stimulation with near-CF 
Table 1. Effect of furosemide injection on the frequency tuning of basilar membrane responses to clicks

Click peak pressure (dB SPL)

\begin{tabular}{|c|c|c|c|c|c|c|c|c|}
\hline Frequency tuning & & 35 & 45 & 55 & 65 & 75 & 85 & 95 \\
\hline \multicolumn{9}{|l|}{ Chinchilla L14 } \\
\hline \multirow[t]{2}{*}{ Frequency of maximum sensitivity $(\mathrm{Hz})$} & Pre & & & 9766 & 9609 & 9453 & 8594 & 6641 \\
\hline & Post & & & $*$ & & 5513 & & 5234 \\
\hline \multirow[t]{2}{*}{ 10-dB bandwidth $(\mathrm{Hz})$} & Pre & & & 2787 & 3348 & 4773 & 6386 & 7129 \\
\hline & Post & & & $*$ & & 6446 & & 6126 \\
\hline \multirow[t]{2}{*}{$Q_{10}$} & Pre & & & 3.50 & 2.87 & 1.98 & 1.35 & 0.93 \\
\hline & Post & & & * & & 0.86 & & 0.85 \\
\hline \multicolumn{9}{|l|}{ Chinchilla L13 } \\
\hline \multirow[t]{2}{*}{ Frequency of maximum sensitivity $(\mathrm{Hz})$} & Pre & 8984 & 8984 & 8984 & 8984 & 8281 & 8281 & \\
\hline & Post & & $*$ & * & 7578 & 7813 & 7891 & \\
\hline \multirow[t]{2}{*}{ 10-dB bandwidth $(\mathrm{Hz})$} & Pre & 1272 & 1368 & 1601 & 1922 & 2042 & 2349 & \\
\hline & Post & & $*$ & $*$ & 2905 & 3355 & 3723 & \\
\hline \multirow[t]{2}{*}{$Q_{10}$} & Pre & 7.06 & 6.57 & 5.61 & 4.67 & 4.05 & 3.53 & \\
\hline & Post & & $*$ & $*$ & 2.61 & 2.33 & 2.12 & \\
\hline
\end{tabular}

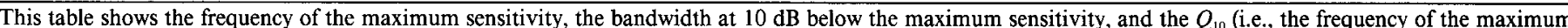

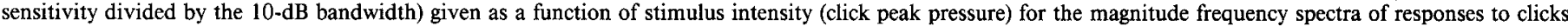

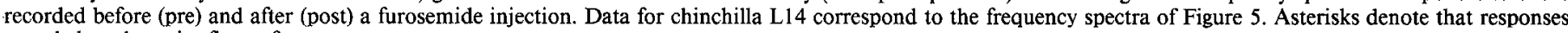
were below the noise floor of measurement.

tones there were large phase lags for all stimulus levels below $70-80 \mathrm{~dB}$. The furosemide-induced lags were as large as $97^{\circ}$ (in L14) and $125^{\circ}$ (in L13) between 30 and $60 \mathrm{~dB}$ SPL but decreased in magnitude at higher stimulus intensities. At or above $80 \mathrm{~dB}$, there was little phase change.

Figure 9 provides a summary of the immediate effects of furosemide injection upon the phases of responses to tones at $C F(A)$ and well below CF $(B)$ in 5 cochleae. Postinjection response phases, from which preinjection values have been subtracted, are plotted against stimulus intensity. While responses to below-CF tones did not undergo substantial phase changes (with but one, unexplained, exception), furosemide invariably induced phase lags (averaging some $77^{\circ}$ at 50 and $60 \mathrm{~dB}$ SPL) in responses to moderate-intensity $\mathrm{CF}$ tones. The lags grew smaller at higher intensities, disappearing at $80 \mathrm{~dB}$ SPL. This dependence of phase lag on stimulus intensity closely paralleled the above-noted intensity dependence of furosemide-induced response-magnitude changes (Figs. 2, 3, 5). In addition, there was a clear positive correlation $(r=0.78)$ between the initial sensitivity of basilar membrane responses and the size of the phase lags. The dependence of furosemide-induced phase lag on the state of the cochlea corresponds appropriately to the previously discussed correlation between response-magnitude decrements and preinjection basilar membrane sensitivity.

\section{Discussion}

\section{Summary of results and conclusions}

(1) Intravenous injection of furosemide reversibly altered the mechanical response to sound of the basilar membrane of the chinchilla cochlea.

(2) Furosemide caused reductions in the magnitude of basilarmembrane responses to both tones and clicks. Reductions were largest (up to $61 \mathrm{~dB}$, averaging 25-30 dB) at low stimulus intensities at the CF and small or nonexistent at high intensities and at frequencies far removed from CF.

(3) Furosemide also induced response-phase lags that were largest at low stimulus intensities (averaging $77^{\circ}$ ) and were confincd to frequencies close to CF.
(4) Because furosemide exerts its cochlear effects via disruption of hair cell mechanical-to-electrical transduction, the present results imply that the outer hair cells feed back mechanically upon the basilar membrane.

\section{Relationship of present data to previous measurements of basilar membrane vibration and otoacoustic emissions}

In accordance with previous findings in relatively normal cochleae (squirrel monkey: Rhode, 1971; guinea pig: Sellick et al., 1982; Patuzzi and Sellick, 1983; chinchilla: Robles et al., 1986b), the present study indicates that basilar membrane responses to near-CF tones grow nonlinearly at moderate stimulus intensities, with a slope substantially less than $1 \mathrm{~dB} / \mathrm{dB}$, while responses to lower-than-CF tones grow linearly at all intensities. Additionally, responses of one basilar membrane to intense ncar-CF tones (Fig. 2) suggest that, as previously proposed on theoretical grounds (Patuzzi et al., 1989; see also Johnstone et al., 1986), the compressive nonlinear growth does not persist at such high stimulus intensities; rather, the input-output curve approaches a linear growth rate.

The time-domain responses to clicks measured with laser velocimetry (Fig. 4; see also Ruggero and Rich, 1991, their Fig. 6) consist of relatively undamped oscillations resembling the reverse-correlation functions for responses to noise of low-CF cochlear afferents (de Boer and Kuyper, 1968; de Boer and de Jongh, 1978). Prior investigations of basilar membrane responses to clicks (Robles et al., 1976; LePage and Johnstone, 1980) showed poorly tuned responses that varied nonlinearly with stimulus intensity. The present results confirm the finding of nonlinear growth of responses but demonstrate much sharper frequency tuning, comparable to the frequency tuning of responses to tones in relatively intact cochleae. The frequency spectra of responses to clicks (Fig. 5; see also Ruggero and Rich, 1991, their Fig. 8) change with stimulus intensity in a manner that is, at least qualitatively, consistent with basilar membrane responses to tones (Sellick et al., 1982; Robles et al., 1986b): responses to low-intensity clicks are more sharply tuned than responses to higher-intensity clicks (Table 1). 


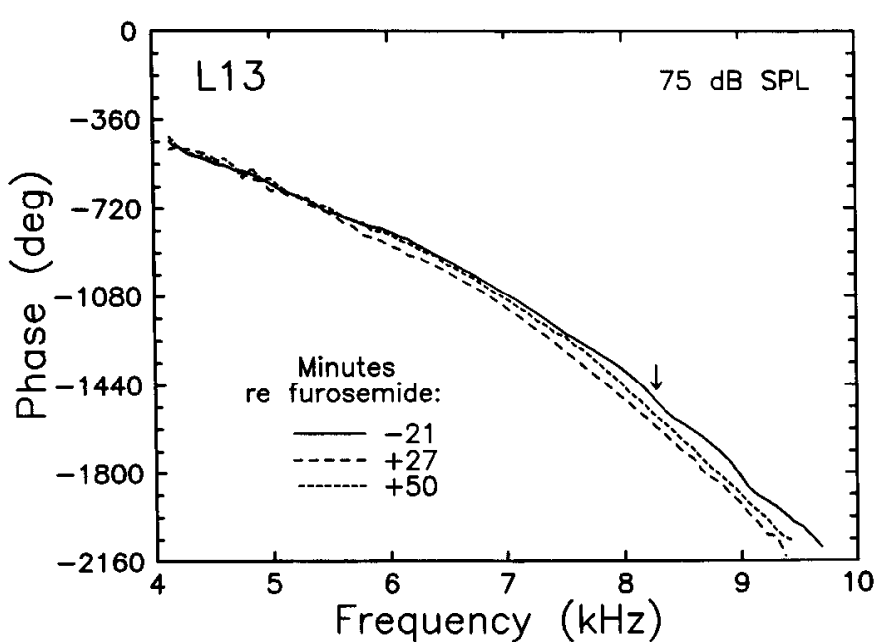

Figure 6. Effects of a furosemide injection upon the phase-versusfrequency characteristic of responses to clicks in basilar membrane L13. Phases were computed via Fourier transformation of the time-averaged responses to $75-\mathrm{dB}$ clicks. The arrow indicates the frequency at which the largest response occurred before furosemide injection. Negative phase values indicate phase lags.

The changes induced in basilar membrane motion by furosemide injection are comparable to those brought about by death (Rhode, 1973; Sellick et al., 1982; Robles et al., 1986b). Such changes include linearization of the input-output curves for responses to $\mathrm{CF}$ tones, loss of response sensitivity and frequency tuning, and reduction in the frequency of maximal sensitivity. Perhaps more surprising, these effects of furosemide also resemble those of 2-tone suppression (Robles et al., 1986a, 1989). The similarity of the effects of death, furosemide injection, and 2-tone suppression probably reflects a common chain of events and morphological substrates, with the outer hair cells playing the central role.

The present findings suggest that alterations of otoacoustic emissions induced by loop diuretics (Anderson and Kemp, 1979; Hubbard and Mountain, 1990) arise in basilar-membrane mechanics. It is puzzling, however, that both reductions (Anderson and Kemp, 1979) and enhancements (Hubbard and Mountain, 1990) of otoacoustic emissions have been reported.

\section{The primary cochlear site of action of furosemide}

Systemic furosemide administration causes a rapid but reversible disruption of cochlear function, as reflected in the endocochlear potential, receptor potentials, auditory-nerve thresholds, and, as shown in the present work, basilar membrane vibration. There are only 2 structures that have been seriously considered as primary sites of action of furosemide in the cochlea: the stria vascularis and the hair cells. It is worth emphasizing that, to the extent that hair-cell receptor potentials are decreased by transient dysfunction either of stria vascularis (which reduces the endocochlear potential) or of the hair cells themselves, both mechanisms implicate the hair cells as mediators of the effect of furosemide on basilar membrane mechanics. ${ }^{1}$ In the last part of the discussion, we will review evidence that specifically implicates the outer (rather than inner) hair cells.

\footnotetext{
${ }^{1}$ Nuttall (1985) suggested that changes in the electric field of scala media might conceivably alter the properties of the tectorial membrane, in turn causing changes in hair-cell responses.
}

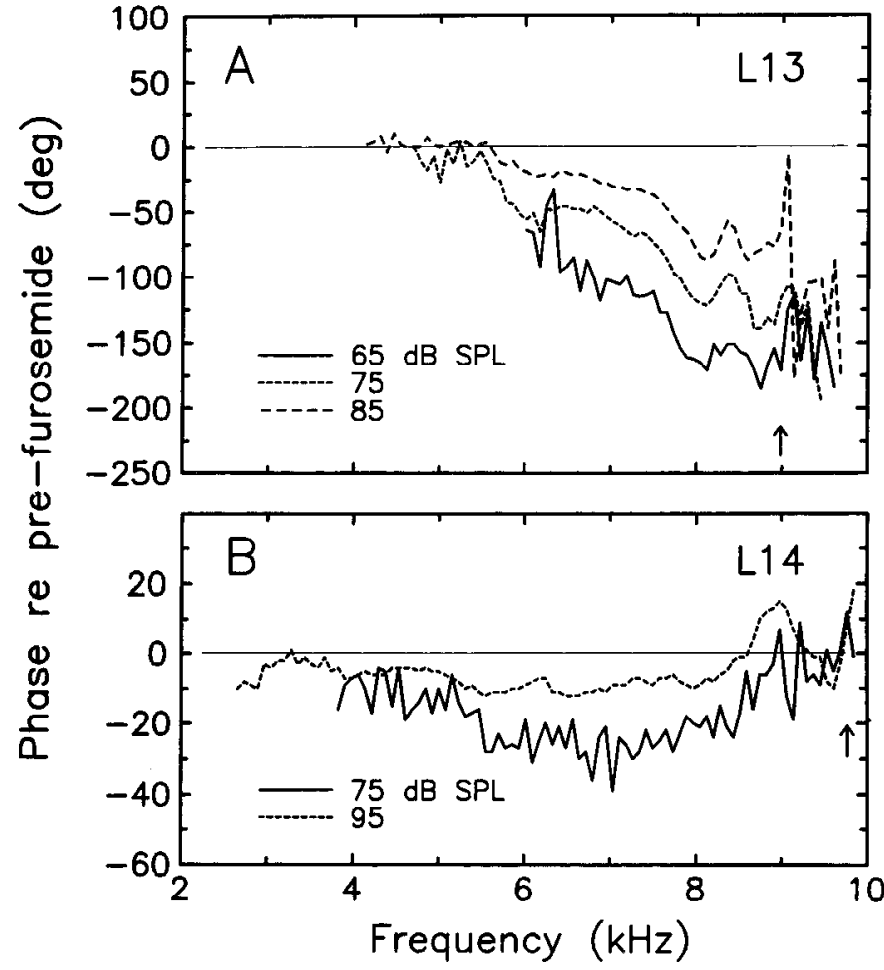

Figure 7. Stimulus-level dependence of the effect of a furosemide injection upon the phases of responses to clicks in basilar membranes $\mathrm{L} 13$ $(A)$ and $\mathrm{L} 14(B)$. Phases of postinjection responses are plotted against frequency after subtracting the phases of preinjection responses for the same stimulus level. Positive values indicate phase leads; negative values phase lags. The arrows indicate $\mathrm{CF}$ as reflected in responses to lowlevel clicks. Note that different ordinate scales are used in the 2 panels.

Upon intravenous injection of furosemide, there is a rapid and reversible decrease of the large $(80 \mathrm{mV})$ positive electrical potential normally present in the endolymph-filled scala media of the cochlea (Chodynicki and Kostrzewska, 1974; Brusilow, 1976; Kusakari et al., 1978). Three main lines of evidence indicate that the drop in endolymphatic potential results from a primary cochlear effect of furosemide on the stria vascularis (Brown and Feldman, 1978).

(1) There is strong and direct evidence that the stria vascularis is the active source of the positive endocochlear potential (Tasaki and Spyropolous, 1959; Prazma, 1975; Melichar and Syka, 1987; Offner et al., 1987).

(2) When furosemide is injected intraarterially or intravenously, the endocochlear potential decays within seconds (Brown and McElwee, 1972) or 2-3 min (Brown and McElwee, 1972; Kusakari et al., 1978), respectively. In contrast, much longer delays (many minutes) occur when furosemide is perfused through scala tympani (Kusakari et al., 1978; Sewell, 1984b). This indicates that the primary cochlear site of action must be immediately accessible to the arterial blood supply, as is the stria vascularis, and (functionally) remote from the perilymph. Furthermore, when furosemide is instilled into perilymph, the perilymph concentrations required to alter cochlear function are 2 orders of magnitude greater $\left(10^{-4}-10^{-3} \mathrm{M}\right.$; Evans and Klinke, 1982) than perilymph concentrations when the endocochlear potential is maximally reduced as a result of intravenous furosemide injection $\left(1.5 \times 10^{-6} \mathrm{M}\right.$; Rybak et al., 1979). This evidence thus tends to rule out a primary site of action in the hair cclls or other cells of the organ of Corti, whose basolateral 


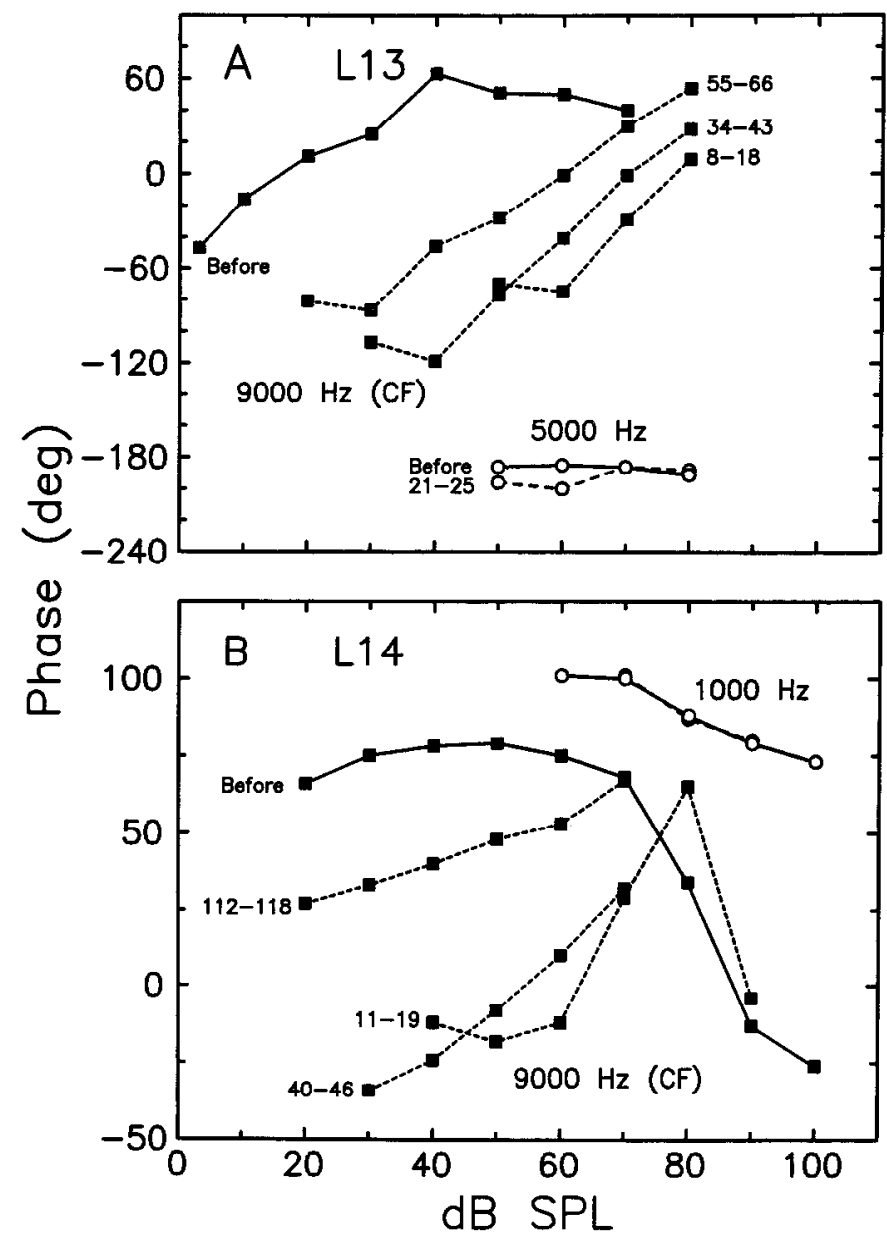

Figure 8. Effect of a furosemide injection upon the phases of responses to tones at CF (squares) and at one lower frequency (circles) in basilar membranes L13 $(A)$ and L14 $(B)$. Phases are shown as a function of stimulus level for responses immediately preceding the injection (solid lines) and at various postinjection times (broken lines) indicated, in minutes, for each curve.

membranes are closely related to the perilymph in scala tympani.

(3) Upon intravenous injection of furosemide, there are morphological alterations of stria vascularis whose time course of onset and recovery resembles those of alterations in the endocochlear potential (Pike and Bosher, 1980).

Although it seems that furosemide causes no permanent damage to the organ of Corti (Federspil and Mausen, 1973; Brown et al., 1979), there have been reports of functional (Syka and Melichar, 1981, 1985), morphological (Forge and Brown, 1982; Comis et al., 1990), and histochemical (Akiyoshi, 1981) abnormalities in hair cells immediately following furosemide injections, raising the possibility that furosemide interacts directly with the cochlear sensory cells. Nevertheless, there is substantial evidence that other electrophysiological effects of furosemide, including changes in cochlear microphonics and auditory-nerve responses, result principally from a reduction in the endocochlear potential ${ }^{2}$ (see reviews by Rybak, 1982, 1986; Sewell, 1984a).

${ }^{2}$ Although furosemide also causes some decrease in the endolymphatic $\mathrm{K}^{+}$ concentration (Brusilow, 1976; Rybak and Morizono, 1982), this effect is probably too small and slow to account for rapid changes in cochlear microphonics or auditory-nerve responses.

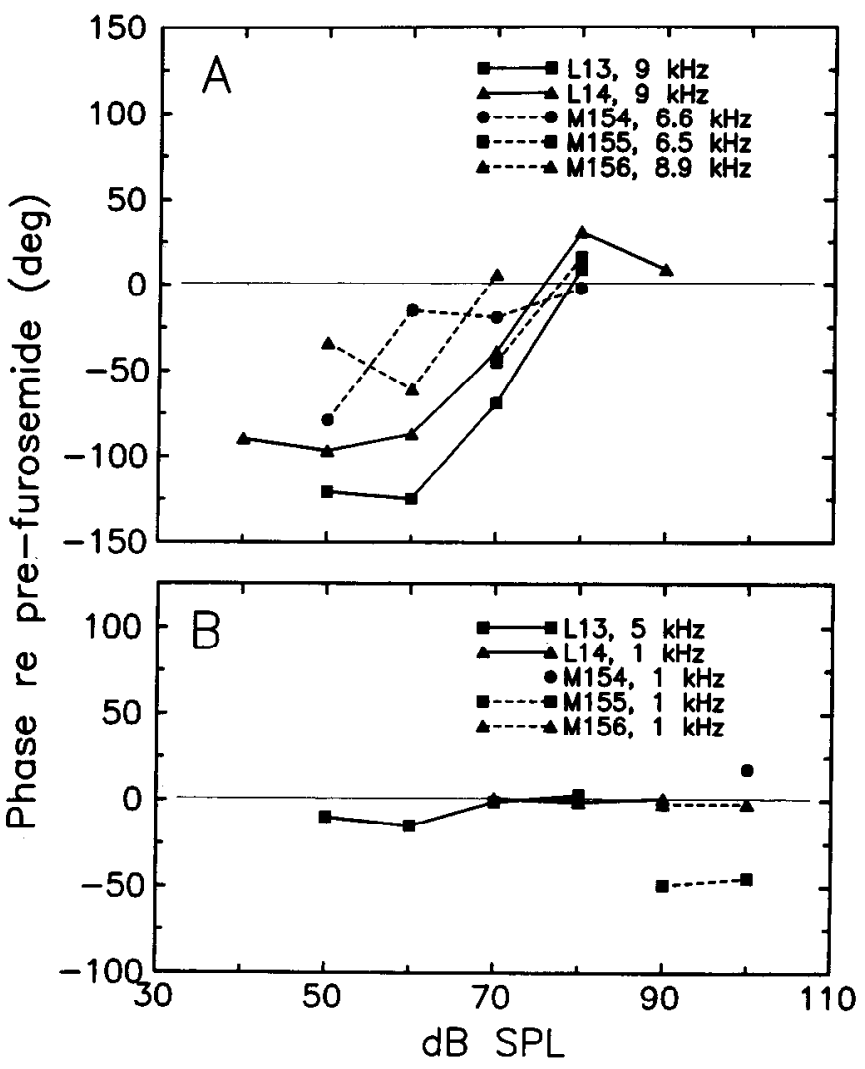

Figure 9. Effect of furosemide injection upon the phases of responses to $\mathrm{CF}(A)$ and lower-frequency tones $(B)$ for 5 basilar membranes, as a function of stimulus level. The phases of the earliest available response immediately following furosemide injection are plotted after subtraction of preinjection phases.

Because the transduction currents across the apical surfaces of the hair cells are proportional to the sum of the endocochlear potential and the potential that exists across their basolateral surfaces (Davis, 1965; Honrubia and Ward, 1969; Russell, 1983), there is a concurrent reduction in the hair-cell receptor potentials, as deduced from cochlcar microphonics recordings (Mathog et al., 1970; Goldman et al., 1973). Using values of +80 $\mathrm{mV}$ for the endocochlear potential and $-80 \mathrm{mV}$ for the intracellular potential of outer hair cells relative to the perilymph, it can be calculated that complete abolishment of the endocochlear potential should reduce the cochlear microphonics by $50 \%$ or $6 \mathrm{~dB}$, which is in agreement with experimental values (e.g., Syka and Melichar, 1981, 1985; Hubbard and Mountain, 1990). Given such reduction of receptor potentials, it is not surprising that the thresholds of responses of cochlear afferents, most of which innervate exclusively inner hair cells, should be elevated by furosemide (Evans and Klinke, 1982; Sewell, 1984b). What is of greater significance is that the threshold elevation is much larger at each afferent's CF than at other frequencies. Because the sharp frequency tuning of cochlear inner hair cells and cochlear afferents has its origin in the frequency tuning of the basilar membrane (Khanna and Leonard, 1982; Sellick et al., 1982; Robles et al., 1986b), the frequency dependence of the effects of furosemide upon cochlear-afferent responses has been interpreted as reflecting a corresponding reduction in the magnitude of basilar membrane vibration, such reduction resulting from the disruption of the feedback of outer hair cells upon the basilar membrane (Mountain et al., 1983; Patuzzi et al., 1989). 
The present findings conclusively show that basilar membrane vibration sensitivity and frequency tuning are indeed reduced by furosemide.

\section{Models of bidirectional cochlear transduction}

The present results generally support models of bidirectional cochlear transduction put forth by Mountain (1991; see also Mountain et al., 1983) and Patuzzi et al. (1989; see also Yates, 1990). These models postulate that the outer hair cells and the basilar membrane participate in a high-gain feedback loop, ${ }^{3}$ and that many basilar membrane response properties result from the inherently nonlinear input-output characteristic of forward transduction in outer hair cells (Russell et al., 1986). The model of Patuzzi et al. (1989) incorporates an empirical function that allows computing basilar membrane responses at $\mathrm{CF}$ on the basis of outer hair cell currents. Presuming that intravenous furoscmidc injections of $50-100 \mathrm{mg} / \mathrm{kg}$ reduce the endocochlear potential from +80 to $0 \mathrm{mV}$ (Rybak and Morizono, 1982), the model predicts a decrease in basilar membrane vibration of 36 $\mathrm{dB}$, which is somewhat larger than our experimental values of 25-30 dB. This is reasonable, because our data were obtained when there was some deterioration of the cochlea (usually small, e.g., 3-12 dB, but in one case amounting to $27 \mathrm{~dB}$ ). The model of Patuzzi et al. (1989) also mimics very well the dependence on stimulus intensity that we have observed in the furosemideinduced changes in basilar membrane response magnitude (cf. Fig. 2 with Patuzzi et al., 1989, their Fig. 10).

\section{Significance of the sensitivity of basilar membrane responses to furosemide}

The present findings provide direct evidence-the most conclusive yet-that the basilar membrane and the outer hair cells are joined in a feedback loop. It seems almost indisputable that the outer hair cells are the only ones in the organ of Corti that can link furosemide-induced changes in receptor potentials to alterations of basilar membrane vibration: only the outer hair cells can act both as sensory receptors and as motors capable of controlling basilar membrane mechanics.

Supporting cells of the organ of Corti do not sustain intrinsic receptor currents (Russell and Sellick, 1978); in contrast, there is ample evidence that hair cells are the cochlear mechanoreceptors (Russell et al., 1986). Their receptor potentials are importantly determined by the endocochlear potential (Davis, 1965; Honrubia and Ward, 1969; Russell, 1983) and are, accordingly, reduced by furosemide injections (Mathog et al., 1970; Goldman et al., 1973).

The strongest evidence excluding the inner hair cells from a mechanical feedback role upon the basilar membrane, and by default implicating the outer hair cells, comes from studies of the effects of DC currents on cochlear responses to sound. When positive currents are passed into scala media, cochlear microphonics (Tasaki and Fernández, 1952; Tasaki et al., 1954; Konishi and Yasuno, 1963; Honrubia and Ward, 1969) and auditorynerve responses (Tasaki and Fernández, 1952) are enhanced, while the opposite occurs upon application of negative currents.

\footnotetext{
${ }^{3}$ Some authors (Comis et al., 1981; Klinke et al., 1981; Evans and Klinke, 1982) have expressed concern about the relatively small changes in cochlear microphonics induced by furosemide vis-à-vis large changes in auditory-nerve excitation thresholds. In fact, such disproportion of effects is appropriate to the extent that the positive-feedback loop linking the outer hair cells and the basilar membrane has sufficiently high gain (Patuzzi et al., 1989; Mountain, 1991).
}

Such effects are qualitatively consistent with the Davis (1965) hypothesis. Most important, however, the auditory-nerve effects are confined to near-CF frequencies and are largest at low stimulus levels (Teas et al., 1970; Hubbard et al., 1983). Thus, the effects of applying negative current to scala media are, appropriately, similar to effects of lowering the endolymphatic potential by means of furosemide injection (Evans and Klinke, 1982; Sewell, 1984b). Nuttall (1985) clarified the mechanism of action of current injection by studying the receptor potentials of inner hair cells. When positive or negative currents were injected into scala media, the inner hair cell responses to sound were enhanced or decreased, respectively, in a frequency- and intensity-dependent manner. In contrast, when the currents were applied to the inner hair cell by means of an intracellular microelectrode, the effects were neither intensity nor frequency dependent. These results may be generalized to experiments involving furosemide injections: alterations of inner hair cell receptor potentials induced by furosemide probably are not responsible for the reductions in basilar membrane frequency tuning and sensitivity. The obvious alternate candidate is the outer hair cell.

Further evidence singling out outer hair cells as mediators of the mechanical effects of furosemide can be cited. The outer hair cells are the only organ of Corti cells that respond to variations in transmembrane voltage by generating mechanical forces capable of changing their length in vitro (Brownell et al., 1985; Ashmore, 1987; Santos-Sacchi and Dilger, 1988) and, probably, of pushing or pulling the basilar membrane in vivo. Additionally, the position of outer hair cells is advantageous for exerting force on the basilar membrane: they are situated in the organ of Corti (roughly) halfway across the basilar membrane, where the membrane undergoes its largest excursion, and their stereocilia are firmly connected to the tectorial membrane. In contrast, inner hair cells are located on the edge of the (nearly immobile) bony spiral lamina, and their stereocilia are only weakly attached to the tectorial membrane or do not contact it at all (Lim, 1986).

In conclusion, the present demonstration that furosemide reversibly and frequency-specifically reduces the mechanical response of the basilar membrane to sound constitutes the most definitive evidence yct that the basilar membrane and the outer hair cells are components of a mechanical to electrical to mechanical feedback loop. Interruption (opening) of such a loop (due to damage to outer hair cells and causing basilar membrane vibrations to be abnormally small) is probably the most common origin of sensorineural hearing loss in humans (Patuzzi et al., 1989).

\section{References}

Akiyoshi M (1981) Effect of loop diuretics on hair cells of the cochlea in guinea pigs. Histological and histochemical study. Scand Audiol [Suppl] 14:185-198.

Anderson SD, Kemp DT (1979) The evoked cochlear mechanical response in laboratory primates. Arch Otorhinolaryngol 224:47-54.

Anderson DJ, Rose JE, Hind JE, Brugge JF (1971) Temporal position of discharges in single auditory nerve fibers within the cycle of a sinewave stimulus: frequency and intensity effects. J Acoust Soc Am 49: 1131-1139.

Ashmore JF (1987) A fast motile response in guinea-pig outer hair cells: the cellular basis of the cochlear amplifier. J Physiol (Lond) 388: 323-347.

Brown MC, Nuttall AL, Masta RI (1983) Intracellular recordings from cochlear inner hair cells: effects of stimulation of the crossed olivocochlear efferents. Science 222:69-72. 
Brown RD, Feldman AM (1978) Pharmacology of hearing and ototoxicity. Annu Rev Pharmacol Toxicol 18:233-252.

Brown RD, McElwee TW (1972) Effects of intra-arterially and intravenously administered ethacrynic acid and furosemide on cochlear $\mathrm{N}_{1}$ in cats. Toxicol Appl Pharmacol 22:589-594.

Brown RD, Manno JE, Daigneault EA, Manno BR (1979) Comparative acute ototoxicity of intravenous bumetanide and furosemide in the purebred beagle. Toxicol Appl Pharmacol 48:157-169.

Brownell WE, Bader CR, Bertrand D, de Ribaupierre Y (1985) Evoked mechanical responses of isolated cochlear outer hair cells. Science 227:194-196.

Brusilow SW (1976) Propanolol antagonism to the effect of furosemide on the composition of endolymph in guinea pigs. Can J Physiol Pharmacol 54:42-48.

Chodynicki S, Kostrzewska A (1974) Wplyw furosemidu i kwasu etakrynowego na potencjal endolimfatyczny swinki morskiej (Effects of furosemide and ethacrynic acid on the endolymphatic potential in guinea pigs). Otolaryngol Pol 28:5-8.

Comis SD, Leng G, Pratt SR (1981) The effects of frusemide, bumetanide, and piretanide on the guinea pig cochlea and auditory nerve. Scand Audiol [Suppl] 14:85-94.

Comis SD, Osborne MP, Jeffries DJR (1990) Effect of furosemide upon morphology of hair bundles in guinea pig cochlear hair cells. Acta Otolaryngol (Stockh) 109:49-56.

Dallos P (1988) Cochlear neurobiology: some key experiments and concepts of the past two decades. In: Auditory function: neurobiological bases of hearing (Edelman GM, Gall WE, Cowan WM, eds), pp 153-188. New York: Wiley.

Davis H (1965) A model for transducer action in the cochlea. Cold Spring Harbor Symp Quant Biol 30:181-189.

Davis H (1983) An active process in cochlear mechanics. Hear Res 9:79-90.

de Boer E, de Jongh HR (1978) On cochlear encoding: potentialities and limitations of the reverse-correlation technique. J Acoust Soc Am 63:115-135.

de Boer E, Kuyper P (1968) Triggered correlation. IEEE Trans Biomed Eng BME-15:169-179.

Evans EF, Klinke R (1982) The effects of intracochlear and systemic furosemide on the properties of single cochlear nerve fibres in the cat. J Physiol (Lond) 331:409-428.

Federspil P, Mausen H (1973) Experimentelle untersuchungen zur Ototoxicität des Furosemids. Res Exp Med 161:175-184.

Forge A, Brown AM (1982) Ultrastructural and electrophysiological studies of acute ototoxic effects of furosemide. Br J Audiol 16:109116.

Geisler CD, Rhode WS (1982) The phases of basilar-membrane vibrations. J Acoust Soc Am 71:1201-1203.

Goldman WJ, Bielinski TC, Mattis PA (1973) Cochlear microphonic potential responsc of the dog to diurctic compounds. Toxicol Appl Pharmacol 25:259-266.

Guinan JJ Jr (1986) Effect of efferent neural activity on cochlear mechanics. Scand Audiol [Suppl] 25:53-62.

Honrubia V, Ward PH (1969) Dependence of the cochlear microphonics and the summating potential on the endocochlear potential. J Acoust Soc Am 46:388-392.

Hubbard AE, Mountain DC (1983) Alternating current delivered into the scala media alters sound pressure at the eardrum. Science 222 : $510-512$.

Hubbard AE, Mountain DC (1990) Haircell forward and reverse transduction: differential suppression and enhancement. Hear Res 43:269272.

Hubbard AE; Voigt HF, Mountain DC (1983) Injection of direct current into scala media altcrs auditory-ncrve responsc properties. Assoc Res Otolaryngol Midwinter Meet Abstr 6:103-104.

Johnstone BM, Patuzzi R, Yates GK (1986) Basilar membrane measurements and the travelling wave. Hear Res 22:147-153.

Kemp DT (1978) Stimulated acoustic emissions from within the human auditory system. J Acoust Soc Am 64:1386-1391.

Khanna SM, Leonard DGB (1982) Basilar membrane tuning in the cat cochlea. Science 215:305-306.

Kim DO, Molnar CE, Matthews JW (1980) Cochlear mechanics: nonlinear behavior in two-tone responses as reflected in cochlear-nervefiber responses and in ear-canal sound pressure. J Acoust Soc Am 67: 1704-1721.

Klinke R, Göttl KH, Roesch A (1981) Testing strategy for ototoxic side effects. Scand Audiol [Suppl] 14:95-107.
Konishi T, Yasuno T (1963) Summating potential of the cochlea in the guinea pig. J Acoust Soc Am 35:1448-1452.

Kusakari J, Ise I, Comegys TH, Thalmann I, Thalmann R (1978) Effect of ethacrynic acid, furosemide, and ouabain upon the endolymphatic potential and upon high energy phosphates of the stria vascularis. Laryngoscope 88:12-37.

LePage E, Johnstone BM (1980) Nonlinear mechanical behaviour of the basilar membrane in the basal turn of the guinea pig cochlea. Hear Res 2:183-189.

Lim DJ (1986) Functional structure of the organ of Corti: a review. Hear Res 22:117-146.

Mathog RH, Thomas WG, Hudson WR (1970) Ototoxicity of new and potent diuretics. Arch Otolaryngol 92:7-13.

Melichar I, Syka J (1987) Electrophysiological measurements of the stria vascularis potentials in vivo. Hear Res 25:35-43.

Mountain DC (1980) Changes in endolymphatic potential and crossed olivocochlear bundle stimulation alter cochlear mechanics. Science 210:71-72.

Mountain DC (1991) An active stiffness model of cochlear function. I. Linear analysis. Hear Res, in press.

Mountain DC, Hubbard AE (1989) Rapid force production in the cochlea. Hear Res 42:195-202.

Mountain DC, Hubbard AE, McMullen TA (1983) Electromechanical processes in the cochlea. In: Mechanics of hearing (de Boer E, Viergever MA, eds), pp 119-126. Delft, The Netherlands: Delft UP.

Nuttall AL (1985) Influence of direct current on DC receptor potentials from cochlear inner hair cells in the guinea pig. J Acoust Soc Am 77: $165-175$.

Offner FF, Dallos P, Cheatham MA (1987) Positive endocochlear potential: mechanism of production by marginal cells of stria vascularis. Hear Res 29:117-124.

Patuzzi R, Sellick PM (1983) A comparison between basilar membrane and inner hair cell receptor potential input-output functions in the guinea pig cochlea. J Acoust Soc Am 74:1734-1741.

Patuzzi R, Johnstone BM, Sellick PM (1984) The alteration of the vibration of the basilar membrane produced by loud sound. J Acoust Soc Am 13:99-100.

Patuzzi RB, Yates GK, Johnstone BM (1989) Outer hair receptor currents and sensorineural hearing loss. Hear Res 42:47-72.

Pike DA, Bosher SK (1980) The time course of the strial changes produced by intravenous furosemide. Hear Res 3:79-89.

Prazma J (1975) Electroanatomy of the lateral wall of the cochlea. Arch Otorhinolaryngol 209:1-13.

Rhode WS (1971) Observations of the vibration of the basilar membrane in squirrel monkeys using the Mössbauer technique. J Acoust Soc Am 49:1218-1231

Rhode WS (1973) An investigation of post-mortem cochlear mechanics using the Mössbauer effect. In: Basic mechanisms in hearing (Møller AR, ed), pp 49-63. New York: Academic.

Rhode WS, Robles L (1974) Evidence from Mössbauer experiments for nonlinear vibration in the cochlea. J Acoust Soc Am 55:588-596.

Robles L, Rhode WS, Geisler CD (1976) Transient response of the basilar membrane measured in squirrel monkey using the Mössbauer effect. J Acoust Soc Am 59:926-939.

Robles L, Ruggero MA, Rich NC (1986a) Mössbauer measurements of the mechanical response to single-tone and two-tone stimuli at the base of the chinchilla cochlea. In: Peripheral auditory mechanisms (Allen JB, Hall JL, Hubbard A, Neely ST, Tubis A, eds), pp 121128. Berlin: Springer.

Robles L, Ruggero MA, Rich NC (1986h) Basilar membrane mechanics at the base of the chinchilla cochlea. I. Input-output functions, tuning curves, and response phases. J Acoust Soc Am 80:1364-1374.

Robles L, Ruggero MA, Rich NC (1989) Nonlinear interactions in the mechanical response of the cochlea to two-tone stimuli. In: Cochlear mechanisms - structure, function and models (Wilson JP, Kemp DT, eds), pp 369-375. London: Plenum.

Ruggero MA, Rich NC (1983) Chinchilla auditory-nerve responses to low-frequency tones. J Acoust Soc Am 73:2096-2108.

Ruggero MA, Rich NC (1990a) Application of laser velocimetry to the measurement of basilar membrane vibrations. J Acoust Soc Am 87:S101.

Ruggero MA, Rich NC (1990b) Systemic injection of furosemide alters the mechanical response to sound of the basilar membrane. In: Mechanics and biophysics of hearing (Dallos P, Geisler CD, Matthews JW, Ruggero MA, Steele C, eds), pp. 314-321. New York: Springer. Ruggero MA, Rich NC (1991) Application of a commercially man- 
ufactured Doppler-shift laser velocimeter to the measurement of basilar-membrane vibration. Hear Res, in press.

Russell IJ (1983) Origin of the receptor potential in inner hair cells of the mammalian cochlea-evidence for Davis' theory. Nature 301: 334-336.

Russell IJ, Sellick PM (1978) Intracellular studies of hair cells in the mammalian cochlea. J Physiol (Lond) 284:261-290.

Russell IJ, Richardson GP, Cody AR (1986) Mechanosensitivity of mammalian auditory hair cells in vitro. Nature 321:517-519.

Rybak LP (1982) Pathophysiology of furosemide ototoxicity. J Otolaryngol 11:127-133.

Rybak LP (1986) Ototoxic mechanisms. In: Neurobiology of hearingthe cochlea (Altschuler RA, Hoffman DW, Bobbin RP, eds), pp 441454. New York: Raven.

Rybak LP, Morizono T (1982) Effect of furosemide upon endolymph potassium concentration. Hear Res 7:223-231.

Rybak LP, Green TP, Juhn SK, Morizono T, Mirkin BL (1979) Elimination kinetics of furosemide in perilymph and serum of the chinchilla. Acta Otolaryngol (Stockh) 88:382-387.

Santos-Sacchi J, Dilger JP (1988) Whole cell currents and mechanical responses of isolated outer hair cells. Hear Res 35:143-150.

Sellick PM, Patuzzi R, Johnstone BM (1982) Measurement of basilar membrane motion in the guinea pig using the Mössbauer technique. J Acoust Soc Am 72:131-141.

Sewell WF (1984a) The relation between the endocochlear potential and spontaneous activity in auditory nerve fibres of the cat. J Physiol (Lond) 347:685-696.

Sewell WF (1984b) The effects of furosemide on the endocochlear potential and auditory-nerve fiber tuning curves in cats. Hear Res 14 305-314.
Siegel JH, Kinl DO (1982) Efferent neural control of cochlear mechanics? Olivocochlear bundle stimulation affects cochlear biomechanical nonlinearity. Hear Res 6:171-182.

Syka J, Melichar I (1981) Comparison of the effects of furosemide and ethacrynic acid upon the cochlear function in the guinea pig. Scand Audiol [Suppl] 14:63-69.

Syka J, Melichar I (1985) The effect of loop diuretics upon summating potentials in the guinea pig. Hear Res 20:267-273.

Tasaki I, Fernández C. (1952) Modification of cochlear microphonics and action potentials by $\mathrm{KCl}$ solution and by direct currents. J Neurophysiol 15:497-512.

Tasaki I, Spyropolous CS (1959) Stria vascularis as a source of the endocochlear potential. J Neurophysiol 22:149-155.

Tasaki I, Davis H, Eldredge DH (1954) Exploration of cochlear potentials in guined pig with a microelectrode. J Acoust Soc Am 26: 765-773.

Teas DC, Konishi T, Wernick JS (1970) Effects of electrical current applied to cochlear partition on discharges in individual auditorynerve fibers. II. Interaction of electrical polarization and acoustic stimulation. J Acoust Soc Am 47:1527-1537.

Weiss T (1982) Bidirectional transduction in vertebrate hair cells: a mechanism for coupling mechanical and electrical processes. Hear Res 7:353-360.

Yates GM (1990) The basilar membrane nonlinear input-ouput function. In: Mechanics and biophysics of hearing (Dallos P, Geisler CD, Matthews JW, Ruggero MA, Steclc C, eds), pp. 106-113. New York: Springer. 